Acknowledgements Supported by funding from Novartis Pharmaceuticals.

\section{P153 PREVALENCE, SEVERITY AND CONSEQUENCES OF THROMBOCYTOPENIA IN SYSTEMIC LUPUS ERYTHEMATOSUS - SINGLE CENTRE COHORT ANALYSIS}

${ }^{1}$ Tatiana Pires, ${ }^{2}$ Raquel Caparrós-Ruiz, ${ }^{3}$ Pedro Gaspar, ${ }^{4}$ David Isenberg. ${ }^{1}$ Serviço de Medicina 1, Centro Hospitalar de Leiria, Leiria, Portugal; ${ }^{2}$ UGC de Reumatologia, Instituto de Investigación Biomédica de Málaga, Hospital Regional Universitario de Málaga, Málaga, Spain; ${ }^{3}$ Serviço de Medicina 2, Hospital Santa Maria, Centro Hospitalar Universitário Lisboa Norte, Lisbon, Portugal; ${ }^{4}$ Centre for Rheumatology, Dept. of Medicine, University College Hospital, London, UK

\subsection{6/lupus-2020-eurolupus. 196}

Background Thrombocytopenia is a common hematological feature of Systemic Lupus Erythematosus (SLE), affecting 10$40 \%$ of patients. Our objective was to characterize the frequency of thrombocytopenia in SLE and determine its time of onset during the course of the disease and its severity. We also sought to identify factors predicting the development of thrombocytopenia.

Methods Single centre cohort analysis of 707 patients with SLE followed for up to 40 years. We reviewed the patients' clinical notes identifying the presence of thrombocytopenia, its time of onset and ascertained other clinical and serological features of the disease. Thrombocytopenia was classified as mild $\left(100-149 \times 10^{9} / \mathrm{L}\right)$, moderate $\left(31-99 \times 10^{9} / \mathrm{L}\right)$ or severe $\left(\leq 30 \times 10^{9} / \mathrm{L}\right.$ platelets). It was also classified as asymptomatic, with minor bleeding or with major bleeding. A case control analysis was conducted, using the patients in the lupus cohort that did not develop thrombocytopenia as a control group.

Results $23 \%$ of patients $(n=162)$ had thrombocytopenia prior to or during the course of SLE. Twenty-three patients (14.2\%) had isolated Idiopathic Thrombocytopenic Purpura (ITP) before the diagnosis of SLE. Median follow-up time was 19 years $(\mathrm{IQR}=13)$. Most patients $(\mathrm{N}=67,41.4 \%)$ had mild thrombocytopenia. Most patients $(n=96,59.3 \%)$ developed asymptomatic thrombocytopenia and only 6 patients $(3.7 \%)$ had major bleeding events in the context of thrombocytopenia. Patients of South Asian ethnicity had an increased risk of developing of thrombocytopenia $(\mathrm{OR}=3.33)$ compared to Caucasian patients $(\mathrm{p}=0.002)$. Haemolytic Anaemia $(\mathrm{OR}=5,49 ; \mathrm{p}<0.001)$ and kidney involvement $(\mathrm{OR}=1.81$, $\mathrm{p}=0.004)$ were also associated with a higher risk of developing thrombocytopenia.

Conclusions Although a common manifestation of SLE, thrombocytopenia may be a marker of severe disease being associated with other organ involvement, notably lupus nephritis and other haematological complications, such as haemolytic anaemia.

\section{P154 ANTIMALARIAL TREATMENT AND MINIMIZING PREDNISONE REDUCE THE RISK OF INFECTION IN SLE PATIENTS: A 24-MONTH PROSPECTIVE COHORT STUDY}

\footnotetext{
${ }^{1}$ Ana Prata, ${ }^{1}$ Mariana Luís, ${ }^{1}$ Helena Assunção, ${ }^{1,2}$ Luís Inês. ${ }^{1}$ Dept. of Rheumatology, Centro Hospitalar Universitário de Coimbra, Coimbra; ${ }^{2}$ Faculty of Health Sciences, University of Beira Interior, Covilhã, Portugal
}

Background/Purpose Infections are a leading cause of death and morbidity in SLE patients. SLE-related factors, medications, and comorbidities can be risk factors for infection in these patients. There is a need to better define predictors and strategies to reduce the risk of infection in SLE. This study aims to identify clinical predictors of infection in SLE patients.

Methods Prospective cohort study of 24-month follow-up. We included consecutive patients fulfilling ACR'97 and/or SLICC'12 classification criteria for SLE followed-up at an academic lupus clinic. Acute infections occurring after inclusion were prospectively identified based on patient inquiry, clinical evaluation and laboratory data collected at each visit, scheduled at 1-6-month intervals. Acute infections were categorized as: (a) any type; (b) bacterial; (c) severe. For each infection outcome, survival analysis for time to first infection was conducted with log-rank tests of potential baseline predictors (including clinical, analytical, immunological and treatment factors), followed by multivariate Cox proportional hazards models with an estimation of hazard ratios (HR) with 95\% confidence intervals (95\%CI).

Results The study population included 259 patients. During a mean follow-up of $23.3 \pm 3.5$ months, $58.7 \%, 36.3 \%$ and $6.5 \%$ of the patients had any type, bacterial and severe infections, respectively. In the multivariate Cox models: (a) for infection of any type, prednisone $>5 \mathrm{mg} /$ day was predictive (HR=1.95, 95\%CI 1.26-3.03, $\mathrm{p}=0.003)$, while males had lower risk $(\mathrm{HR}=0.48$, 95\%CI $0.26-0.89, \mathrm{p}=0.02)$; (b) for bacterial infection, antimalarials were protective $(\mathrm{HR}=0.49$, 95\% $0.26-0.93, \mathrm{p}=0.03$ ) and males had lower risk $(\mathrm{HR}=0.20,95 \% \mathrm{CI} 0.06-0.62, \mathrm{p}=0.005)$; (c) for severe infection, prednisone $>7.5 \mathrm{mg}$ /day $(\mathrm{HR}=4.32$, 95\%CI 1.39-13.40, $\mathrm{p}=0.011)$ was predictive, while antimalarials were protective $(\mathrm{HR}=0.18,95 \% \mathrm{CI} 0.06-0.51, \mathrm{p}=0.001)$. SLEDAI score, leukopenia, neutropenia, lupus nephritis, and immunosuppressants were not predictive of infection.

Conclusion The risk of infection in SLE patients is lower in patients treated with antimalarials. Minimizing the prednisone dose below $7.5 \mathrm{mg} /$ day reduces the risk of infection.

\section{\begin{tabular}{l|l} 
P155 & ABSTRACT WITHDRAWN
\end{tabular}}

